\title{
Infrared spectra of some fructans
}

\author{
M. Grube*, M. Bekers, D. Upite and E. Kaminska \\ Institute of Microbiology and Biotechnology, University of Latvia, Kronvalda blvd. 4, LV 1586 Riga, \\ Latvia
}

\begin{abstract}
The FT-IR spectra of fructan - inulin (RAFTILINE), widely applied in the food industry and crystalline fructose as the main component of fructans, were studied. Special interest was to study the spectra of the levan precipitate and fructan syrup - produced by Zymomonas mobilis during the fermentation on sucrose-based medium.

It was shown that levan precipitate and fructose syrup does not contain lipids and nucleic acids. Levan precipitate consists of $\sim 93 \%$ of fructose and admixture of glucose, mannan and enzyme - levansucrase. Fructan polymer inulin consists principally of linear chains of fructosyl units linked by a $\beta(2-1)$ bonds ended by a glycosyl unit. The links between the molecules are of a very special type: the $\beta(2-1)$ form (2) [8]. The bacterial fructans of the levan type are high molecular weight polymers, i.e., they are composed of $\beta$-(2,6)-fructosyl-fructose linked molecules and side chains [17]. The FT-IR spectra of levan, apart from inulin's, in the carbohydrate region 900-1200 cm $\mathrm{cm}^{-1}$, shows overlapping broad band with maximum at $\sim 1030 \mathrm{~cm}^{-1}$ and stronger absorption at $\sim 940 \mathrm{~cm}^{-1}$. The differences in both spectra could be caused by different structure and glucose, sucrose and mannan influence.
\end{abstract}

Keywords: IR-spectroscopy, levan, fructose syrup, inulin

\section{Introduction}

Fructose or fruit sugar, is a simple sugar found in honey, fruit and different plants. It is sweeter than glucose and sucrose. Chemically it is a monosaccharide with the empirical formula $\mathrm{C}_{6} \mathrm{H}_{12} \mathrm{O}_{6}$ - the same as glucose but differs from it in structure. It is best obtained by hydrolysis of polyfructose - inulin that is carbohydrate of plant origin naturally occuring in significant amounts [8].

Inulin is a polymer of fructans and consists principally of linear chains of fructosyl units linked by $\beta(2-1)$ bonds ended by a glycosyl unit [9]. Native inulin is a mixture of poly- and oligosaccharides which almost all have the chemical structure $\mathrm{GFn}(\mathrm{G}=$ glucose, $\mathrm{F}=$ fructose, and $\mathrm{n}=$ number of fructose units linked to one another). The links between the molecules are of a very special type: the $\beta(2-1)$ form (2), which makes these molecules indigestible for all higher animals [8] and has significant "dietary fiber effects" often comparable to pectins. The concept of dietary fiber, first described in the context of the hypothesis developed by Burkitt and Trowell in 1975, covers actually a series of complex compounds which are, according to the current most widely accepted physiological definition, "the sum of polysaccharides and lignins that are not hydrolyzed by the endogenous secretion of the human digestive tract" [1].

Fructans are a diverse group of polysaccharides that contains two or more $\beta$-linked fructose units. Fructans containing from 2 to 9 fructose units are named fructooligosaccharides (FOS). In the most prominent structural polymer types, inulin and levan, the fructose chain emerges from the fructose part of a sucrose molecule, proceeding via $\beta 2 \rightarrow 1$ and $\beta 2 \rightarrow 6$ linkages, respectively [10]. Fructans are naturally found not only in plants, but also in bacteria and fungi, probably serving very different functions. Most bacterial fructans are high molecular weight polymers of the levan type, i.e., they are composed

\footnotetext{
"Corresponding author. Tel.: +371 703 4886; Fax: +371 703 4885; E-mail: grube@ lanet.lv.
} 
of $\beta$-(2,6)-fructosyl-fructose linked molecules and side chains [17]. Levans are part of the exopolysaccharide that protects the cells from desiccation, helps in surface attachment, and is - in some plant pathogenic species - involved in preventing the invading bacteria from being recognized by the host defense system [13,14]. Levan is extracellulary produced by different bacteria Bacillus subtilis, Erwinia herbicola [7] and Zymomonas mobilis [20]. Z. mobilis is a unique bacterium among the microbial evolutionary world and it's taxonomic position has not been fully established. In a sucrose-based medium this gram-negative, ethanol-producing bacterium produces various by-products: levan of high molecular mass [4], sorbitol, gluconic acid, and FOS [19]. Levan is viscous, biologically active, non-toxic and can be used as thickener or stabilizer in the food, pharmaceutical and cosmetic industries and is a good raw material for fructose production, acts as immunomodulator, and is applied as blood plasma substitute, prolongator of medicine, and a cholesterol lowering agent [22].

FOS are known as sweeteners with reduced energetic value, stimulators of probiotics [23]. In our laboratory has been developed a new product - fructan syrup [3] obtained from Z. mobilis sucrose fermentation. Fructan syrup has a pleasant honey-like taste, serves as a source of prebiotics, and soluble fiber - levan, and is of interest as potential ingredient in foods because of their effects on intestinal flora, functionality, and reduced caloric value.

The aim of our work was to study the IR spectra of our products: levan precipitate and fructan syrup as well as in the food industry widely applied inulin - RAFTILINE, and fructose as the main component of fructans.

\section{Materials and methods}

\subsection{Microorganisms and preparation of the samples}

The levan-producing strain Zymomonas mobilis 113 "S" and a two-stage fermentation process was used as described previously [5]. The culture liquid, containing ethanol, levan, and gluconic acid, was centrifuged at $28600 \mathrm{~g}$, after the second stage of fermentation. The cell-free supernatant $(100 \mathrm{ml})$ was treated with ethanol $(1: 2.5)$ and the obtained sediment is a crude levan suitable for application in the food industry.

Fructan syrup was prepared from sucrose syrup (65\%) using as biocatalyst $5 \mathrm{~g} / 100 \mathrm{~g}$ levanlevansucrase sediment at incubation temperature $45^{\circ} \mathrm{C}$ during $48 \mathrm{~h}$.

Inulin was obtained from ORAFTI (Belgium) as a commercial food additive RAFTILINE.

\subsection{Analytical methods}

The cell mass in the culture liquid was determined after centrifugation for $15 \mathrm{~min}$ (at $5000 \mathrm{~g}$ ) and drying at $105^{\circ} \mathrm{C}$. The optical density of a 10 time diluted culture was measured at $590 \mathrm{~nm}$. The ethanol concentration was determined by GLC (Chrom 4, the column Inerton AW-HHDS $+5 \%$ PEG, $T_{\mathrm{t}}=80^{\circ} \mathrm{C}$, $T_{\mathrm{S}}=200^{\circ} \mathrm{C}$ ). The gluconic acid concentration was determined by HPLC (Shimadzu LC-4A, the column Shimadzu SCR $101(\mathrm{H})$, spectrophotometer SPD-2AS, $\lambda=210 \mathrm{~nm}$, the mobile phase $0.01 \mathrm{~N} \mathrm{H}_{2} \mathrm{SO}_{4}$, the flow $1.2 \mathrm{ml} / \mathrm{min}$ at $\left.40^{\circ} \mathrm{C}\right)$. Levan was precipitated by ethanol $(65 \mathrm{v} \%)$ and determined as fructose after hydrolysis of polysaccharide [20]. The glucose, fructose, and sucrose concentrations were determined by HPLC (the column Pinacle Amino $5 \mu \mathrm{m}, 250 \times 4.6$ with a mobile phase, acetonitryle : water $75: 25$, refractive index detector). The yield of FOS was calculated from the estimated sugar content in the levan-free solution before and after hydrolysis. 
Fructan syrup and levan precipitate for IR spectral analyses were dried in thermostat at $45^{\circ} \mathrm{C}, 1.5-$ $3.2 \mathrm{mg}$ of sample were mixed with $1 \mathrm{~g} \mathrm{KBr}$, milled and pelleted. 1.0-2.5 mg of RAFTILINE - inulin or fructose (Aldrich) was mixed with $1 \mathrm{~g} \mathrm{KBr}$, milled and pelleted.

The prepared $\mathrm{KBr}$ pellets of fructose, RAFTILINE (inulin), levane precipitate, and fructan syrup were registered on the FT-IR spectrometer Perkin Elmer Spectrum RXIFT-IR, absorption mode between 700 and $3500 \mathrm{~cm}^{-1}$, resolution $4 \mathrm{~cm}^{-1}, 16$ scans.

\section{Results}

\subsection{Interpretation of the IR spectra of carbohydrates}

Crystalline mono- and oligosaccharides give nice infrared spectra with several absorption lines and carbohydrates are a class of bio-molecules well investigated by vibrational spectroscopy. This has to do with the fact that unlike the nucleic acids, the proteins, or the lipids these biomolecules lack prominent polar, infrared-activated functional groups with heteroatoms and multiple bonds. The predominance of $\mathrm{C}-\mathrm{C}$ and $\mathrm{C}-\mathrm{O}$ bonds in carbohydrates and the similar mechanical properties of these bonds give rise to broad, unresolved infrared absorption bands. The specificity of carbohydrates arises from the geometry of the many $\mathrm{O}-\mathrm{H}$ groups and the configuration of the $\mathrm{C}-\mathrm{O}, \mathrm{C}-\mathrm{C}$, and $\mathrm{C}-\mathrm{H}$ bonds in the skeletal base configuration [15]. The IR-absorption a spectrum of crystalline carbohydrates and absorption band interpretation has been widely reported $[2,6,16,21]$.

The IR spectra of carbohydrates can be divided in three specific spectral regions: $1200-900 \mathrm{~cm}^{-1}$, $3000-2700 \mathrm{~cm}^{-1}$ and $900-600 \mathrm{~cm}^{-1}$.

The spectral region between 1200 and $900 \mathrm{~cm}^{-1}$ is generally dominated by a complex sequence of intensive peaks due mainly to strongly coupled $\mathrm{C}-\mathrm{C}, \mathrm{C}-\mathrm{O}$ stretching and $\mathrm{C}-\mathrm{O}-\mathrm{H}, \mathrm{C}-\mathrm{O}-\mathrm{C}$ deformation modes of various oligo- and polysaccharides [18]. In all carbohydrates the most intensive is a broad band at $\sim 1080 \mathrm{~cm}^{-1}$ caused by $\nu(\mathrm{CC})$ and $\nu(\mathrm{CO})$ vibrations. This band serves as characteristic for IR quantitative analysis of microbial biomass, as is not overlapped by absorption of proteins, lipids or nucleic acids [12]. It has been established that the most intensive absorption bands of carbohydrates in the IR-spectra are: strong complex absorption at $1080 \mathrm{~cm}^{-1}$, and $1170 \mathrm{~cm}^{-1}, 1030 \mathrm{~cm}^{-1}$ (valent stretching vibrations of $\mathrm{COC}$ groups and ring vibrational modes in the composition of cyclic structures) [16].

In the 3000-2700 $\mathrm{cm}^{-1}$ region carbohydrates show few sharp absorption bands: $2930 \mathrm{~cm}^{-1}$ assigned to $\mathrm{C}-\mathrm{H}$ streching (assym) of $\mathrm{CH}_{2}, 2870 \mathrm{~cm}^{-1}$ assigned to $\mathrm{C}-\mathrm{H}$ stretching (sym) of $\mathrm{CH}_{3}$, and $\mathrm{C}-\mathrm{H}$ stretching bands in the range of $2700-3100 \mathrm{~cm}^{-1}$.

The region between 900 and $600 \mathrm{~cm}^{-1}$ exhibits a variety of weak but extremely characteristic features superimposed on an underlying broad spectral contour. This region may contain weakly expressed bands arising from aromatic ring vibrations of phenylalanine, tyrosine, tryptophane, and the various nucleotides. With the exception of only a few peaks (e.g., band near $720 \mathrm{~cm}^{-1}$, resulting from the $>\mathrm{CH}_{2}$ rocking modes of the fatty-acid chains), valid assignments can hardly be achieved. Therefore this region can be referred as "fingerprint region" [18]. Bands at $960 \mathrm{~cm}^{-1}$ and $830 \mathrm{~cm}^{-1}$ are not so intensive, but useful for conformational studies of carbohydrates. In order to identify carbohydrate in a mixture it is necessary to select the characteristic absorption bands.

In the region below $1500 \mathrm{~cm}^{-1}$, most of the normal modes are highly coupled vibrations rather than characteristic group frequencies and is predicted to be a complex ring-mode in each case, nevertheless, the vibrational spectra of carbohydrates in this region are very similar [16]. 


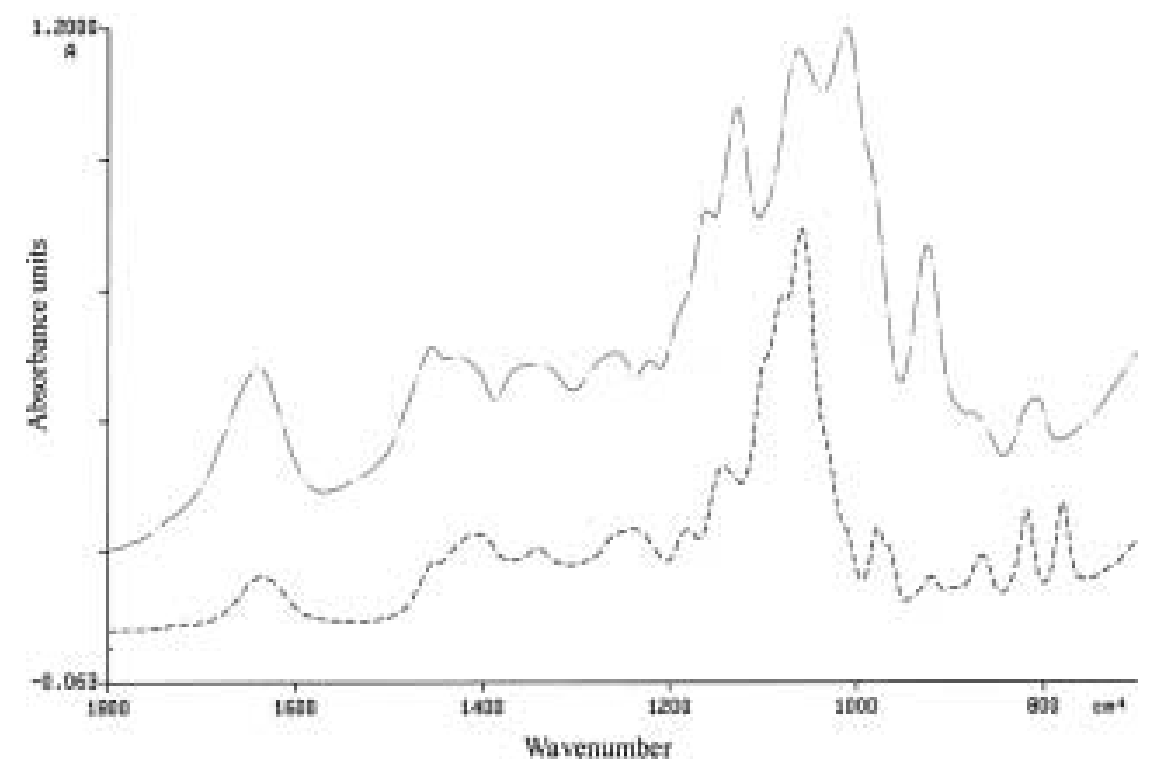

Fig. 1. IR absorption spectra of: fructose - - -, levan precipitate -.---.

\subsection{IR spectra of fructose and inulin}

The most intensive in the IR spectra of fructose (Fig. 1) is a broad band with maximum at $\sim 1050 \mathrm{~cm}^{-1}$ and a shoulder at $1140 \mathrm{~cm}^{-1}$. In $3000-2700 \mathrm{~cm}^{-1}$ region appears one broad band with maximum at $2930 \mathrm{~cm}^{-1}$ and shoulder at $2870 \mathrm{~cm}^{-1}$. The most interesting are two sharp and of similar intensity lines in the "fingerprint region" at 835 and $770 \mathrm{~cm}^{-1}$. These lines could serve as characteristic in studies of mixtures.

RAFTILINE (inulin) contains $6.1 \%$ of other carbohydrates (Table 1). In the IR spectra of inulin (Fig. 2) the most intensive is a broad band with maximum at $\sim 1050 \mathrm{~cm}^{-1}$ with two shoulders at 940 and $1130 \mathrm{~cm}^{-1}$. Broad band with low intensity arises at $1640 \mathrm{~cm}^{-1}$, but can't be used as specific for inulin in biological mixture, as usually in this region is a strong absorption of amides. Like in all carbohydrates two overlapped bands are at $2930 \mathrm{~cm}^{-1}$ and $2870 \mathrm{~cm}^{-1}$.

\subsection{IR spectra of fructan syrup and levan}

Fructan syrup was obtained from Z. mobilis sucrose fermentation by "extracellular-levansucrase" sediment as biocatalyst. Fructan syrup differs from the known FOS products by levan additive (Table 1).

The FT-IR spectra of fructan syrup (Fig. 3) showed very intensive band with maximum at $\sim 1050 \mathrm{~cm}^{-1}$ and small, but separate one at $940 \mathrm{~cm}^{-1}$ that could indicate glucose. Absorbance band in 2800 $3000 \mathrm{~cm}^{-1}$ is similar as in the spectra of inulin and fructose.

The chemical composition of levan precipitate was studied by chromatography and the results are showed in Table 1. It must be mentioned that levan precipitate from Z. mobilis contains some protein admixture - enzyme-levansucrase, in an active complex with levan in small amount [20].

Comparison of levan precipitate and fructose spectra (Fig. 1) proved fructose as the dominating component, but the shape changes of the broad carbohydrate absorption band with maximum at $1080 \mathrm{~cm}^{-1}$, testifies the presence of other carbohydrates and in general fructose polymer form. The main differences 
Table 1

Chemical composition of RAFTILINE, levan precipitate, fructan syrup

\begin{tabular}{lc}
\hline Component & Concentration, \% \\
\hline RAFTILINE ST & \\
Inulin & 93.9 \\
Glucose + fructose & 1.1 \\
Sucrose & 5.0 \\
Levan precipitate & \\
Fructose & 93.0 \\
Glucose & 3.0 \\
Mannan & 2.0 \\
Fructan syrup & \\
Carbohydrates, total & 65.0 \\
FOS & 27.0 \\
Levan & 7.0 \\
Sucrose & 6.0 \\
Glucose + fructose & 22.0 \\
Water & 35.0
\end{tabular}

The energetic value of $100 \mathrm{~g}$

fructan syrup

$186 \mathrm{kcal}$ or $776 \mathrm{~kJ}$

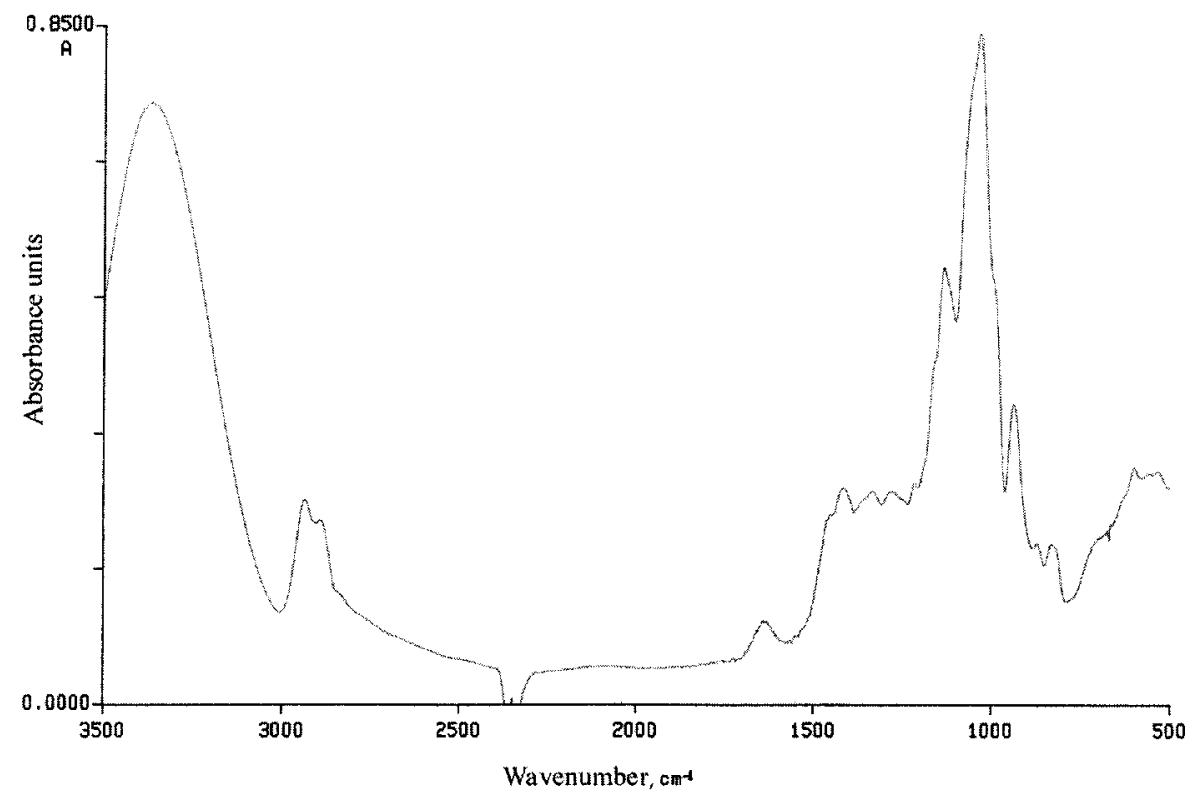

Fig. 2. IR absorption spectra of RAFTILINE.

in fructose and levan precipitate spectra appeared in $800-600 \mathrm{~cm}^{-1}$ region that indicates the presence of other carbohydrates and amino acids.

In the spectra of levan fructose does not show two separate sharp lines at 835 and $770 \mathrm{~cm}^{-1}$, but in this region appears one broad band at $810 \mathrm{~cm}^{-1}$ that could result from overlapping of fructose, glucose and mannan lines $[11,16]$. 


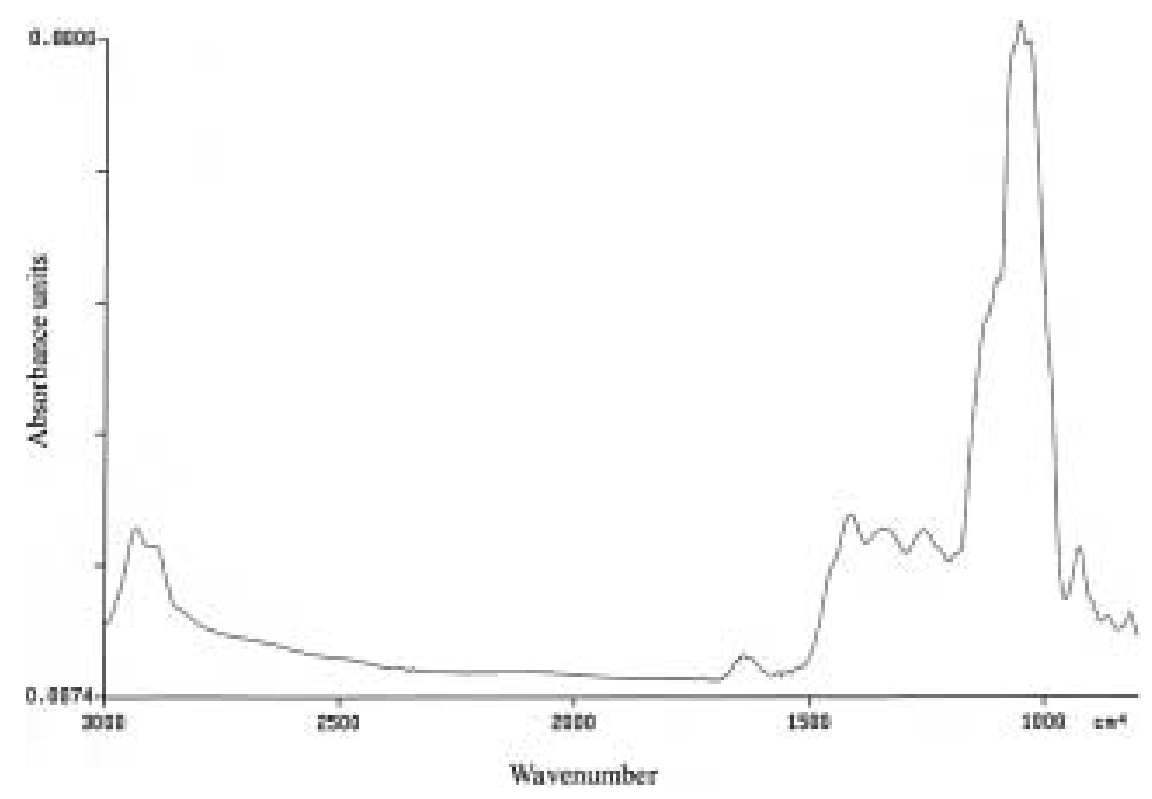

Fig. 3. IR absorption spectra of fructan syrup.

Levan precipitate IR-absorption spectra, showed an increase of broad absorption band at $1600 \mathrm{~cm}^{-1}$. This was interpreted as degradation of proteins, accompanied by an increase of absorption in $1600 \mathrm{~cm}^{-1}$ area caused by free amino acids, simultaneously causing decrease in the intensity of "ammonium" band in $1410 \mathrm{~cm}^{-1}$ area and changing its shape [16]. A characteristic weak feature is often observed around $1400 \mathrm{~cm}^{-1}$, which may be attributed to the symmetric stretching vibrations of $\mathrm{COO}^{-}$functional groups of amino acid side chains, free fatty acids, or other derivatives [18]. Often the precipitates of extracellular polysaccharides contain negligible concentrations of nucleic acids, proteins, and free amino acids $(0.3-3.0 \%)$. For evaluation of the purity of our levan precipitate the spectra was studied to find out the presence of main biochemical components of the microbial cell. Previously we have shown that as the characteristic absorption bands could be used: $1080 \mathrm{~cm}^{-1}$ for carbohydrates, $1250 \mathrm{~cm}^{-1}$ for nucleic acids, $1550 \mathrm{~cm}^{-1}$ for proteins and $2930 \mathrm{~cm}^{-1}$ for lipids [12]. Assessment of levan precipitate spectra showed that levan precipitate did not contain lipids, nucleic acids, but absorption bands in the principal component characteristic band regions in fructose and levan precipitate spectra are of carbohydrate origin, proving that the preparation is free of bacterial cells or their fractions. This investigation proved that the applied levan precipitation method allows obtaining preparation mainly consisting of fructose, with small amounts of amino acids and some other bacterial carbohydrates.

\section{Conclusions}

In the FT-IR spectra of crystalline fructose the most interesting are two sharp lines of a similar intensity in the "fingerprint region" at 835 and $770 \mathrm{~cm}^{-1}$. These lines could serve as characteristic in studies of mixtures with fructan or identification of fructans in microbial biomass.

Fructan polymer inulin consists principally of linear chains of fructosyl units linked by a $\beta(2-1)$ bonds ended by a glycosyl unit. The links between the molecules are of a very special type: the $\beta(2-1)$-form (2), which makes these molecules indigestible for all higher animals [8] and possibly also bacteria. The 
bacterial fructans of the levan type are high molecular weight polymers, i.e., they are composed of $\beta$-(2,6)-fructosyl-fructose linked molecules and side chains [17]. Bacteria can utilize levan apart from inulin. The FT-IR spectra of levan, apart from inulin's, in the carbohydrate region $900-1200 \mathrm{~cm}^{-1}$, shows overlapping broad band with maximum at $\sim 1030 \mathrm{~cm}^{-1}$ and stronger absorption at $\sim 940 \mathrm{~cm}^{-1}$. The differences in both spectra could be caused by the structure and influence of glucose, sucrose and mannan.

It was shown that levan precipitate and fructose syrup does not contain lipids and nucleic acids and the applied precipitation method allows obtaining a preparation mainly consisting of fructose. It was shown that levan precipitate consists of $93 \%$ of fructose and admixture of glucose, mannan and enzymelevansucrase. This admixture does not influence the value of the product and applicability in the functional foods.

\section{References}

[1] N.-G.L. Asp, Classification and methodology of food carbohydrates as related to nutritional effects, Amer. J. Clin. Nut. 61(Suppl.) (1995), 930-937S.

[2] D.M. Back and P.L. Polavarapu, Fourier-transform Infrared spectroscopy of sugars. Structural changes in aqueous solutions, Carbohydrate Res. 121 (1983), 308-311.

[3] M. Bekers, J. Laukevics, D. Upite, E. Kaminska, A. Vigants and U. Viesturs, Method for obtaining fructans from sucrose, Application of Latvian Patent P-00-173, 2000 (in Latvian).

[4] M. Bekers, J. Shvinka, J. Raipulis, M. Laivenieks, L. Pankova and I. Mezbarde, Strain Zymomonas mobilis - producer of levan, Patent of Latvia LV 5709, 1993 (in Latvian).

[5] M. Bekers, J. Shvinka, L. Pankova, M. Laivenieks and I. Mezbarde, Simultaneous sucrose bioconversion into ethanol and levan by Zymomonas mobilis, Appl. Biochem. Biotechnol. 24/25 (1990), 265-274.

[6] J.J. Cael, J.L. Koenig and J. Blackwell, Infrared and Raman spectroscopy of carbohydrates, Carbohydr. Res. 32 (1974), 79-91.

[7] L.G. Cote and J. Ahlgren, Metabolism in microorganisms. Part I: Levan and levansucrase, in: Science and Technology of Fructans, M. Suzuki and N.J. Chatterton, eds, CRC Press, Boca Raton, 1993, pp. 141-168.

[8] P. Coussement, inulin and oligofructose as dietary fiber: analytical, nutritional and legal aspects, in: Complex Carbohydrates in Foods, S.S. Cho, L. Prosky and M. Dreher, eds, Marcel Dekker, Inc., New York, 1999, pp. 203-212.

[9] P. Dysseler, D. Hoffem, J. Fockedey, B. Quemener, J.-F. Thibault and P. Coussement, Determination of inulin and oligofructose in food products, in: Complex Carbohydrates in Foods, S.S. Cho, L. Prosky and M. Dreher, eds, Marcel Dekker, Inc., New York, 1999, pp. 213-227.

[10] M. Ernst, N.J. Chatterton, P. A. Harrison and G. Matitschka, Characterization of fructan oligomers from species of the genus Allium L., Journal of Plant Physiology 153 (1998), 53-60.

[11] M. Grube, M. Bekers, D. Upite and E. Kaminska, IR-spectroscopic studies of Zymomonas mobilis and levan precipitate, Vibrational Spectroscopy 28 (2002), 277-285.

[12] M. Grube, J. Zagreba, E. Gromozova and M. Fomina, Comparative investigation of the macromolecular composition of mycelia forms Thielavia terrestris by infrared spectroscopy, Vibrational Spectroscopy 19 (1999), 301-306.

[13] U. Hettwer, M. Gross and K. Rudolph, Purification and characterization of an extracellular levansucrase from Pseudomonas syringae pv. Phaseolicola, Journal of Bacteriology 177 (1995), 2834-2839.

[14] S. Kasapis, E.R. Morris, M. Gross and K. Rudolph, Solution properties of levan polysaccharide from Pseudomonas syringae pv. phaseolicola, and its possible primary role as a blocker of recognition during pathogenesis, Carbohydr. Polymers 23 (1994), 55-64.

[15] H.H. Mantsch, Historical survey of Infrared and Raman spectroscopy of biological materials, in: Infrared and Raman Spectroscopy of Biological Materials, H.U. Gremlich and B. Yan, eds, Marcel Dekker, Inc., NY, Basel, 2000, pp. 1-14.

[16] R.H. Marchessault, Application of infrared spectroscopy to cellulose and wood polysaccharides, Pure Appl. Chem. 5 (1962), 107-129.

[17] S.P. Marx, S. Winkler and W. Hartmeier, Fermentation of levan-oligosaccharides by different Bifidobacterium spaces, Med. Fac. Landbouww. Univ. Gent 64/5a, 1999, 335-338.

[18] D. Naumann, FT-Infrared and FT-Raman spectroscopy in biomedical research, in: Infrared and Raman Spectroscopy of Biological Materials, H.U. Gremlich and B. Yan, eds, Marcel Dekker, Inc., NY, Basel, 2000, pp. 323-377.

[19] L. Viikari, Carbohydrate metabolism in Zymomonas, Crit. Rew. Biotechnol. 7(3) (1988), 237-261. 
[20] L. Viikari, Formation of levan and sorbitol from sucrose by Zymomonas mobilis, Appl. Microbiol. Biotechnol. 19 (1984), 252-255.

[21] J.W. White, C.R. Eddy, J. Petty and N. Hoban, Infrared identification of disaccharides, Anal. Chem. 20(4) (1958), 506-510.

[22] Y. Yamamoto, Y. Takashi, M. Kawano, M. Jizuka, T. Matsumoti, S. Seiki and H. Yamaguchi, In vitro digestibility and fermentability of levan and its hypocholesterolic effects in rats, J. Nutr. Biochem. 10 (1999), 13-18.

[23] J. Yun, Fructooligosaccharides - occurrence, preparation and application, Enzyme Microbiol. Technol. 19 (1996), 107-117. 


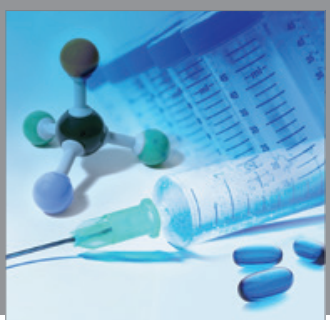

International Journal of

Medicinal Chemistry

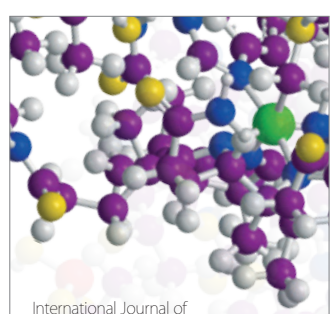

Carbohydrate Chemistry

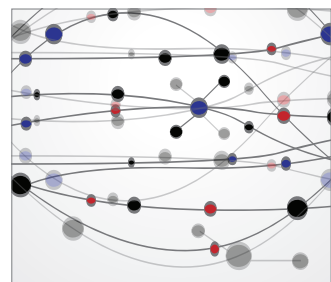

The Scientific World Journal
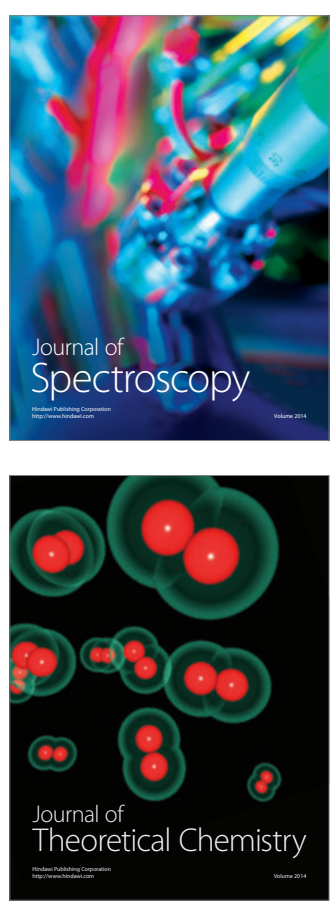
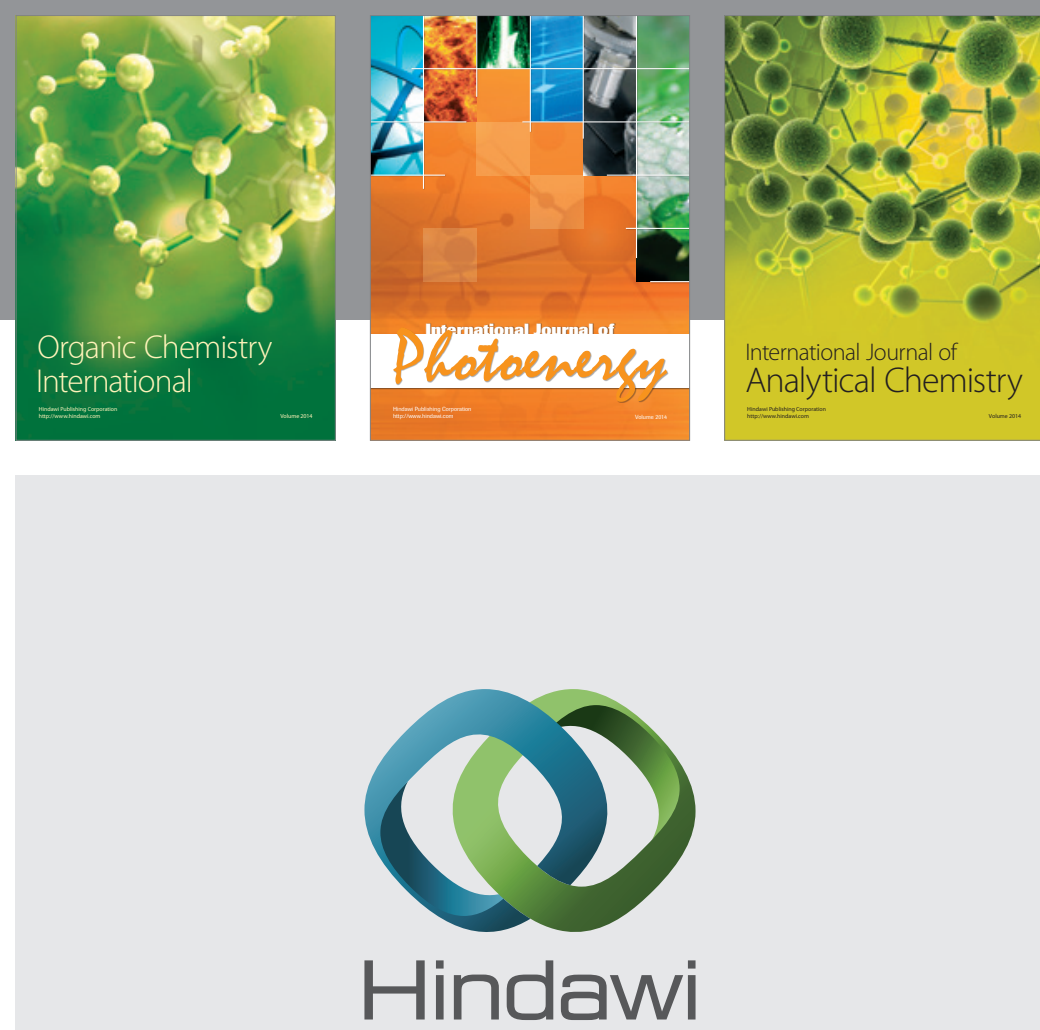

Submit your manuscripts at

http://www.hindawi.com
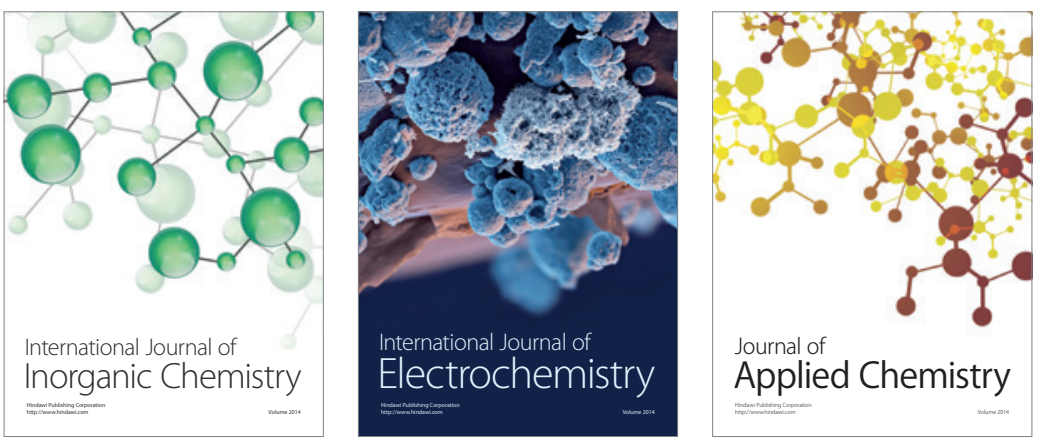

Journal of

Applied Chemistry
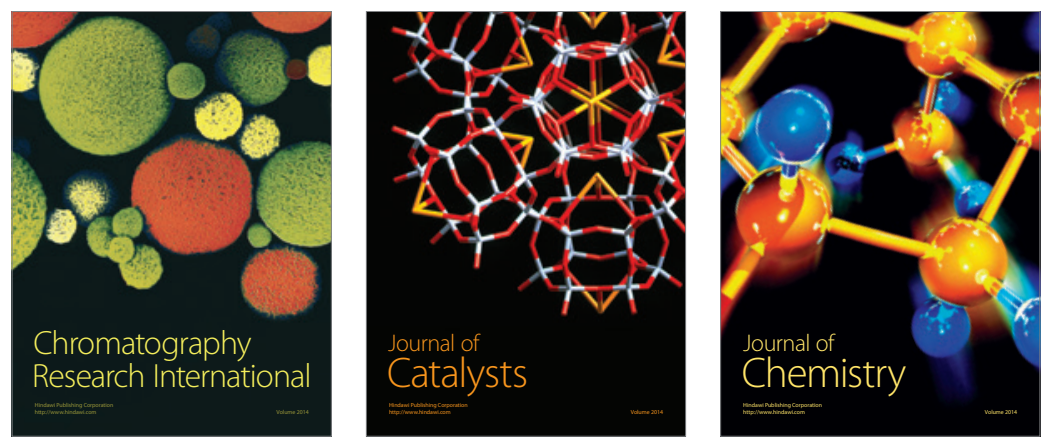
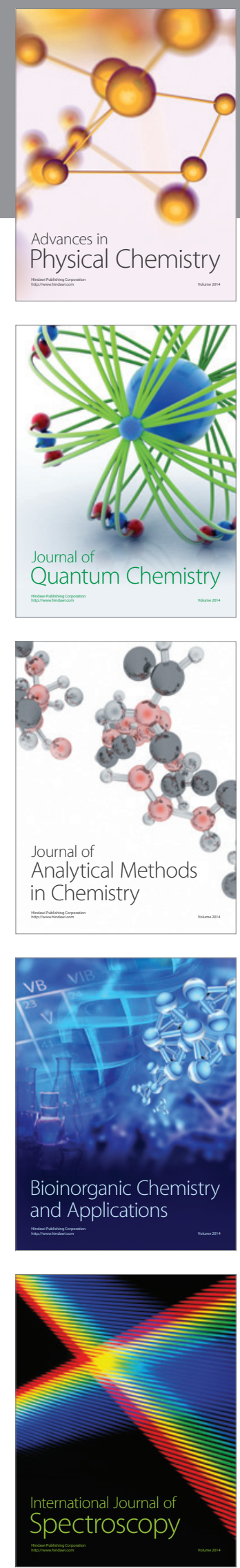